Case Report

\title{
Restoration of highly mutilated endodontically treated multi-rooted teeth using customized interlocking post $\&$ core : A case report
}

\author{
Ajay Jain ${ }^{1}$, Vinaya Bhat ${ }^{2} \&$ Ugrappa Sridevi ${ }^{3}$ \\ ${ }^{1}$ Senior Lecturer , Department of prosthodontics, ${ }^{3}$ Lecturer, Oral M edicine and Radiology, Faculty of Dentistry, AIM ST \\ Dental Institute, AIM ST University, Semeling, Bedong, Malaysia, ${ }^{2}$ Professor, Department of Prosthodontics, \\ A.B. Shetty M emorial Institute of Dental Sciences, Deralakatte, M angalore, Karnataka, India. \\ Correspondence \\ Ajay Jain \\ Senior Lecturer, Department of Prosthodontics, Faculty of Dentistry, AIM ST Dental Institute, AIM ST University, \\ Semeling, Bedong, Malaysia - 08100 \\ Mobile : +6-0109454204E-mail : jainajay9@gmail.com
}

\section{Abstract}

An endodontically treated teeth should have a good prognosis. It can resume full function and serve satisfactorily as an abutment for a fixed dental prosthesis (FDP) or a removable partial dental prosthesis. However, special techniques are needed to restore such a tooth There are various techniques of post and core advocated in the literature. This case report presents the restoration of highly mutilated endodontically treated multi-rooted teeth using customized interlocking post and core technique.

Keywords: Post and core, multirooted, interlocking, mutilated tooth, endodontic

\section{Introduction}

Different techniques of post and core have been described in the literature for the restoration of highly mutilated endodontically treated multirooted teeth ${ }^{1,2}$. The main drawback of these techniques is that only one of the pulp canals is engaged that may compromise the retention. The basic objective is to provide adequate retention of the definitive restoration without jeopardizing the remaining tooth structure ${ }^{3}$. This article presents the restoration of mandibular right molar by using cutomized interlocking post and core which engages both mesial and distal roots to achieve good retention.

\section{Case Report}

A male patient aged 42 reported to the outpatient department, A. B. Shetty Memorial Institute of Dental

\begin{tabular}{|c|}
\hline Access this article online \\
\hline Quick Response Code \\
\hline
\end{tabular}

Sciences, Mangalore with the chief complaint of inability to chew on the right side due to broken tooth in the lower jaw. On examination, the mandibular right first permanent molar was found to be highly mutilated with only very little amount of tooth structure remaining. Tooth was found to be restored with provisional cement, probably zinc oxide eugenol cement (Fig. 1). Patient gave a history of root canal treatment carried out a few years ago. The efficacy of the apical filling was confirmed by an experienced endodontist.

As the amount of the tooth structure remaining was very minimal, the treatment indicated was obviously a post \& core and a crown restoration.

\section{Procedure}

The access filling was removed and the length of the proposed primary canal (distal) was established on the radiograph. The gutta percha points were removed using Peeso reamer (Mani, Inc., U.S.). The other smaller canal was also prepared to receive a smaller extension of the post. The canals were frequently debrided using saline and were enlarged to the desired size and diameter ${ }^{4,5}$. (Fig. 2)

The canals were lubricated with petrolatum jelly. Pattern resin (GC Pattern resin LS, America Inc.) was used with a modified wooden tooth pick to make a direct impression of the distal canal and a core buildup of the entire tooth (Fig. 
3). We used pattern resin instead of inlay wax because pattern resin is more rigid and also it leaves no traces of carbon on burnout, reducing the chances of incomplete casting. While it was still polymerizing, it was removed and checked for completeness and the path of insertion of the post.

Next, an access was created to the mesial canal through the core from the occlusal surface using 702 carbid bur (SS White, Xemax surgical products, Inc.) (Fig. 4). Canal access was enlarged and a dovetail was prepared in the pattern to

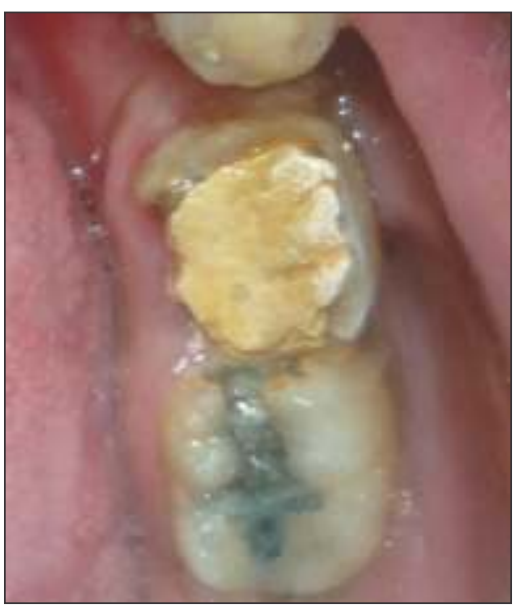

Fig. 1

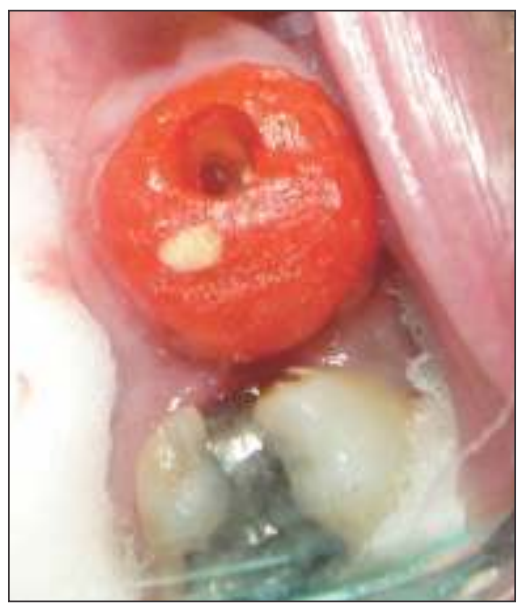

Fig. 4

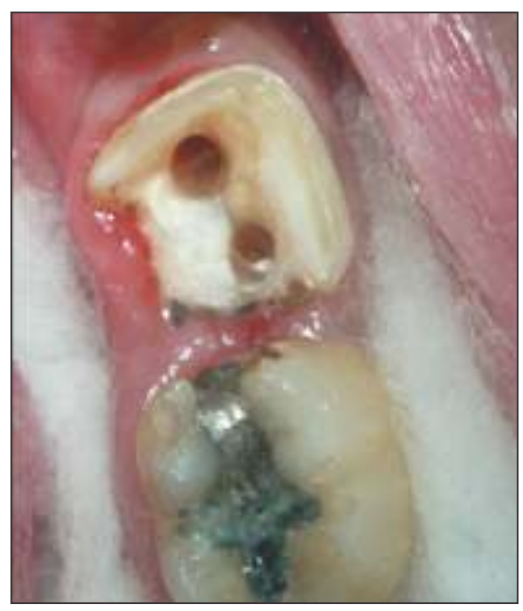

Fig. 2

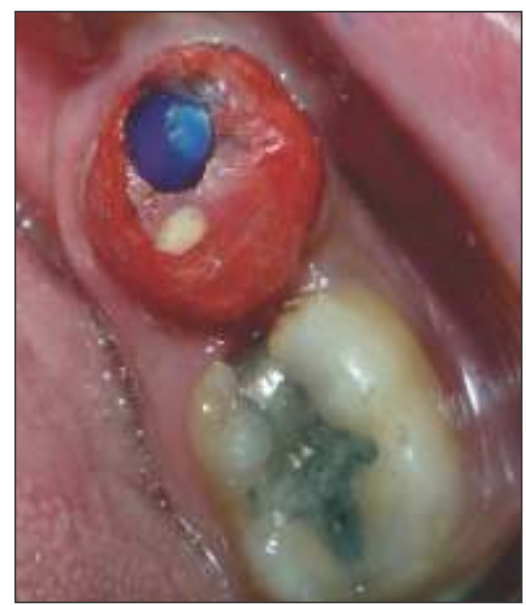

Fig. 5

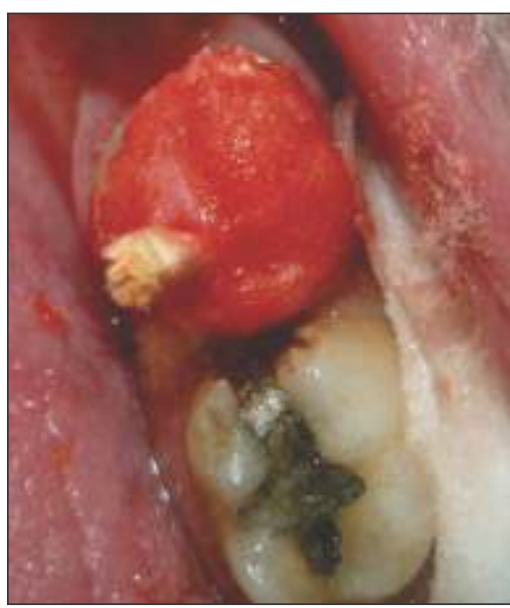

Fig. 3

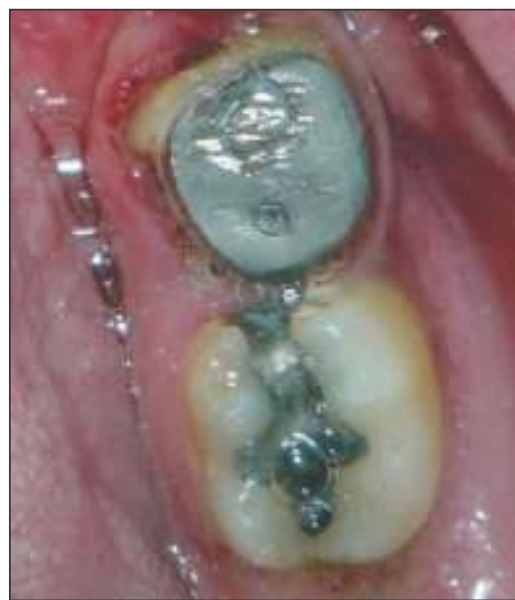

Fig. 6

\section{Discussion}

The wide variety of conditions for restoring endodontically treated teeth indicates that no one technique is suitable for all patients ${ }^{6}$ and most of the techniques are self expedient. ${ }^{3}$ Rosen et al. ${ }^{7}$ described the two or three parts post $\&$ core for the teeth with divergent roots that were cemented get an interlock. Impression of the mesial canal was obtained with the help of softened inlay wax (Shiva products, India) coated onto the shaped tooth pick (Fig.5). Both, the acrylic and the wax patterns were removed from the tooth separately and were cast in type-IV gold alloy. The trimmed and the polished distal post with the core and the mesial key for the interlock were tried on the tooth for the best fit possible. Since they were satisfactory, they were cemented on to the tooth. (Fig. 6) Later, a metal-ceramic crown was given to restore the tooth to occlusion. 
endodontically treated multirooted teeth. Rationale for engaging the distal canal in mandibular molar and palatal canal in maxillary molar has been described by Sapone et al. ${ }^{9}$ and remaining canal can be engaged for more retention of the restoration. In this case report, the author has engaged the distal canal for the post \& core and mesial canal for interlock. Sook-Hyun Nam et al. ${ }^{10}$ compared the fracture resistances and the failure patterns in teeth having different number of coronal walls (zero to four walls) with or without fiber-reinforced composite (FRC) posts and concluded that the fracture resistances decreased significantly in groups with two or fewer walls and FRC post increased fracture resistances significantly, except for the zero-wall group, and optimized the failure patterns. Yang et al. ${ }^{11}$ concluded that mechanical interlocking is the main factor in dislocation of post and core crown and the length of post can be increased from $2 / 3$ to $3 / 4$ of the length of tooth root when prepared in clinic. This direct technique of post and core saves both laboratory time and dental materials i.e. elastomeric impression material, die stone etc that are used for making impression and master cast and the same time gives better detail and precise fit of the restoration as pattern isfabricated by dentist itself.

\section{References}

1. Steele G.D.: Reinforced composite resin foundation for endodontically treated teeth. J Prosthet Dent 1973;30:816-8.

2. Abdullah S.I., Mohammed H., Thayer K.E.: Restoration of endodontically treated teeth. A review. J Can Dent Assoc 1974;4:3005.

3. Michnick B., Raskin R.: A multiple post-core technique. J Prosthet Dent 1978;39:622-6.

4. James L.G.: Preparation of endodontically treated teeth to receive a post-core restoration. J Prosthet Dent 1977;38:413-9.

5. Peroz I., Blankenstein F., Lange K.P., Naumann M.: Restoring endodontically treated teeth with posts and core-A review. Quintessence Int 2005;36:737-46.

6. PatrickE.H., Thomas G.W.: A comparative evaluation of three post and core techniques. J Prosthet Dent 1982;47:177-81.

7. Rosen H.: Operative procedures on mutilated endodontically treated teeth. J Prosthet Dent 1961;11:973-84.

8. Stephen L.W., William L.P.: Direct fabrication of interlocking endodontic posts. J Prosthet Dent 1978;39:115-7.

9. Sapone J., Stanley F.L.: An endodontic-prosthodontic approach to internal tooth reinforcement. J Prosthet Dent 1981;45:164-81.

10. Sook-Hyun Nam et al.: Effect of the Number of Residual Walls on Fracture Resistances, Failure Patterns, and Photoelasticity of Simulated Premolars Restored with or without Fiber-reinforced Composite Posts. J Endod 2010;36:297-301.

11. Yang Y., Chen XM, Wu XH, Yao W, Niu L: Effects of post length on the dislocation of post and core crown. Sichuan Da Xue Xue Bao Yi Xue Ban 2005;36:706-8. 